\title{
INFORMAL CARING IN CENTRAL SYDNEY
}

David Muscatello *

NSW Public Health Officer Training Program

NSW Department of Health

\section{Peter Sainsbury}

Social Health Research Unit

Central Sydney Area Health Service

\section{Chris Rissel}

Health Promotion Unit

Central Sydney Area Health Service

This article describes the prevalence of informal caring in the Central Sydney Area Health Service (CSAHS) compared to that observed Australia-wide. Using data from the 1997 NSW Health Survey, we demonstrate that the prevalence of informal caring in the CSAHS is similar to that observed in larger Australia-wide surveys; and that, based on this limited sample, carers have similar sociodemographic characteristics and health status as non-carers. While this information is useful for health services planning, the analysis highlights some of the difficulties of examining conditions with low prevalence in small-area population surveys.

\section{BACKGROUND}

Approximately five per cent of Australian households have at least one person who is the principal informal carer for someone with a long-term health problem or disability, ${ }^{1}$ and most carers are middle-aged women..$^{2,3}$ There is, however, uncertainty about the association between caregiving and the physical and mental health of the caregiver, ${ }^{2,45}$ and little is known about the needs of carers. Also, there are no data concerning caring within individual area health services in NSW. To assist health services planning, and to allow us to judge how confidently we could rely on information generated by larger Australian surveys, we sought to identify the prevalence of informal caring and the basic sociodemographic characteristics and health status of informal carers in CSAHS.

\section{METHOD}

We analysed data for residents of CSAHS from the 1997 NSW Health Survey. Respondents aged 16 years and over residing in a household with a private telephone participated in a computer-aided telephone interview. ${ }^{6}$ All NSW respondents $(n=17,531)$ were asked core sociodemographic, risk factor, and health status questions. ${ }^{6}$ English speaking residents of CSAHS ( $n=1070)$ were asked additional questions relating to caring.

Carers were identified through a screening question which defined a carer as "someone who looks after a person who is mentally or physically disabled, or who is limited in

\footnotetext{
* Currently Manager, Program for Enhanced Population Health Infostructure, Epidemiology and Surveillance Branch, NSW Department of Health.
}

what they can do by illness or old age'. Of 49 respondents identified as carers, 11 (22 per cent) reported being paid a salary or wages for caring and were excluded. The remaining informal carers (that is, those who were unpaid or received a carer's allowance) were asked how many persons they cared for, their relationship to the care receivers, and the age and physical, mental and emotional condition of the persons being cared for. Prevalence estimates were weighted for the probability of selection based on household size, age and sex to the resident population of CSAHS based on 1996 Census data. ${ }^{6}$

\section{RESULTS}

The response rate to the statewide component of the survey was 68.1 per cent in Central Sydney, resulting in 1,234 completed interviews. ${ }^{6}$ Because area-specific questions were asked only in interviews conducted in English, 1070 (86.7 per cent) respondents were asked the carer screening question. These respondents were slightly, but significantly, more likely to be female, middle-aged and be born in Australia than the overall CSAHS population.

Overall, 3.5 per cent of the Central Sydney population was engaged in informal caring, with most caring being done by persons aged 55 years or over. Slightly more men (3.6 per cent) than women ( 3.3 per cent) reported being engaged in caring, with the greatest difference appearing in the over 55 age group (7.2 per cent of men, 3.6 per cent of women), although these differences were not statistically significant (see Table 2). Of carers, 83.3 per cent (95 per cent CI 70.8 to 95.9) cared for one person, and 16.7 per cent ( 95 per cent CI 4.1 to 29.2) cared for two. Two-thirds of care recipients (or oldest recipient if more than one) were aged 55 years or more $(65.2$ per cent, 95 per cent CI 49.1 to 81.2). Almost one-third of care recipients were the mother of the carer (30.2 per cent, 95 per cent CI 14.7 to 45.6), 18.7 per cent (95 per cent CI 5.6 to 31.9) were the partner, and 15.8 per cent ( 95 per cent CI 3.5 to 28.0 ) were a friend.

We found no statistical association between informal caring and the carer's sex, age, marital status, education, home ownership, social security benefit status, employment status, psychological distress, self-reported health and functioning, smoking status, alcohol intake or physical activity.

Table 3 summarises the major categories of health problems of the 44 care receivers, as identified by their carers. Twenty-eight (63.6 per cent) of the care receivers had one health problem, 13 (29.5 per cent) had two, and three $(6.8$ per cent) had three or four.

\section{DISCUSSION}

Although our sample of informal carers was small, the prevalence of informal caring in CSAHS is consistent with that reported in other Australian studies. ${ }^{1,3}$ This is reassuring for area-based service planners who can now 


\section{TABLE 2}

PREVALENCE OF INFORMAL CARING BY AGE AND SEX IN CENTRAL SYDNEY AREA HEALTH SERVICE, 1997 *

\begin{tabular}{|c|c|c|c|c|c|c|}
\hline \multirow[b]{2}{*}{ Age group } & \multicolumn{2}{|c|}{ Males } & \multicolumn{2}{|c|}{ Females } & \multicolumn{2}{|c|}{ Persons } \\
\hline & $\%$ & (95\% Cl) & $\%$ & (95\% Cl) & $\%$ & $(95 \% \mathrm{Cl})$ \\
\hline $16-29$ years & 3.4 & $(0.0-7.0)$ & 2.9 & $(0.2-5.7)$ & 3.1 & $(0.9-5.4)$ \\
\hline $30-54$ years & 2.3 & $(0.4-4.2)$ & 3.4 & $(1.2-5.7)$ & 2.9 & $(1.4-4.3)$ \\
\hline $55+$ years & 7.2 & $(2.3-12.1)$ & 3.6 & $(0.5-6.8)$ & 5.3 & $(2.5-8.2)$ \\
\hline Total & 3.6 & $(1.8-5.4)$ & 3.3 & $(1.8-4.8)$ & 3.5 & $(2.3-4.7)$ \\
\hline
\end{tabular}

rely on the more detailed and more statistically robust results of national studies with greater confidence. Also consistent with larger studies, carers in CSAHS were not different from non-carers on the sociodemographic and health factors measured, and carers were observed to be a heterogeneous group. ${ }^{2}$ Our finding of a similar prevalence of caring among men and women was unexpected but this study differed from others in that principal and secondary caregivers were not differentiated and there was no definitional minimum on the number of hours spent caring each week.

Our analyses suggest that as carers, care recipients and their social contexts are not homogeneous, future research should focus on the difficulties and needs of specific categories of carers, such as those from disadvantaged backgrounds and those caring for people with different physical and psychiatric disorders. This study does, however, highlight the difficulties of doing this with smallarea population surveys. To enable sub-group analyses to be performed an initial sample of 10,000-20,000 would have been needed-a project well beyond the financial and other resources of most area health services.

CSAHS has a very culturally diverse population (at the 1996 Census 43.7 per cent of the population over five

\section{TABLE 3}

MAJOR HEALTH PROBLEMS, IDENTIFIED BYTHEIR CARERS, OF 44 CARE RECEIVERS, CENTRAL SYDNEY AREA HEALTH SERVICE, NSW, 1997

\begin{tabular}{|lccr|}
\hline Health problem & $\begin{array}{c}\text { First } \\
\text { problem } \\
\text { identified }\end{array}$ & $\begin{array}{c}\text { Additional } \\
\text { problems } \\
\text { identified }\end{array}$ & Total \\
\hline Musculoskeletal & 6 & 4 & 10 \\
Neurological & 9 & 0 & 9 \\
Cardiovascular & 6 & 2 & 8 \\
Psychiatric & 5 & 3 & 8 \\
(excluding dementia) & 5 & 3 & 8 \\
'Old age' & 5 & 0 & 4 \\
Respiratory & 4 & 0 & 3 \\
Dementia & 3 & 6 & 10 \\
Miscellaneous & 4 & 3 & 5 \\
Uncodeable & 2 & 21 & 65 \\
Total & 44 & & \\
\hline
\end{tabular}

years old spoke a language other than English at home), ${ }^{7}$ and it is possible that people from non-English speaking backgrounds (NESB) have different patterns of caring to people of English speaking background. Our results do not relate to adults who required an interpreter to complete the survey (13.3 per cent of the sample) and it is likely that these are the NESB people who are most different in their caring patterns.

Finally, the study highlights the importance of clarifying, either in the screening question or subsequently, whether individuals who care for another person are receiving payment for their caring role. Almost a quarter of the people who answered 'yes' to our screening question were receiving a salary or wages for their caring role.

In summary, the results of area-specific questions in the NSW Health Survey suggested that the prevalence of informal caring in CSAHS is similar to that found in larger surveys that have focused on this issue. However, our experience highlights the difficulties of examining conditions with low prevalence in small-area population surveys.

\section{REFERENCES}

1. Howe AL, Schofield H, Herrman H. Caregiving: a common or uncommon experience? Soc Sci Med 1997; 45(7): 1017 1029.

2. Schofield HL, Herrman HE, Bloch S, Howe A, Singh B. A profile of Australian family caregivers: diversity of roles and circumstances. Aust N Z J Public Health 1997; 21(1): 59-66.

3. Australian Bureau of Statistics. Disability, Ageing and Carers: Summary of findings. Canberra: Australian Bureau of Statistics, 1999. Catalogue no. 4430.0.

4. Payda C. Draper B, Luscombe G, Ehrlich F, Maharaj J. Stress in carers of the elderly. Aust Family Physician 1999; 28(3): 233-237.

5. Livingston G, Manela M, Katona C. Depression and other psychiatric morbidity in carers of elderly people living at home. BMJ 1996; 312(7024): 153-156.

6. NSW Department of Health. NSW Health Survey 1997: Electronic Report [updated 8 Oct 1999, cited 11 Sep 2000 ]. URL: www.health.nsw.gov.au/public-health/hs97.

7. Rissel C, Winchester L. A Demographic profile of the Central Sydney Area Health Service from the 1996 Census. Sydney: Needs Assessment and Health Outcomes Unit, Central Sydney Area Health Service, 1998. 嵒 